Rev Biomed 2004; 15:27-31.

\title{
Comportamiento reproductivo de yeguas Pura Sangre Inglés en un criadero con partos al principio del año.
}

\section{Artículo Original}

Sergio Vázquez-Dueñas ${ }^{1}$, Francisco J. Escobar-Medina², Federico de la Colina-Flores ${ }^{2}$, Sergio HaydenValles $^{1}$

${ }^{1}$ Práctica privada; ${ }^{2}$ Unidad Académica de Medicina Veterinaria y Zootecnia de la Universidad Autónoma de Zacatecas, Calera de Víctor Rosales, Zacatecas, México.

\section{RESUMEN.}

Introducción. Se estudió el comportamiento reproductivo de yeguas Pura Sangre Inglés pertenecientes a un criadero comercial a $19^{\circ} 30^{\prime} \mathrm{N}$ y $119^{\circ} 27^{\prime} \mathrm{O}$, donde se obtienen los partos al principio del año.

Material y métodos. Las hembras se mantuvieron en pastoreo con complemento alimenticio diariamente. Los servicios se realizaron por monta natural del 15 de febrero al 30 de junio. Las yeguas que no concibieron se trataron con luz artificial, adicional al fotoperíodo natural, del 1 de diciembre al 31 de enero. Resultados. El 35.7\%, 17.8\%, 19.4\%, 14.7\% y $12.4 \%$ de los partos se presentaron en enero, febrero, marzo, abril y mayo, respectivamente. Los intervalos del parto al primer celo, primer servicio y la concepción fueron de 14, 25 y 117 días, respectivamente. Se necesitaron 2.83 servicios por concepción. El 51.0\% de las ovulaciones se realizaron en el ovario izquierdo, el $43.9 \%$ en el derecho y el $5.1 \%$ en ambos. El $48.3 \%$ de las gestaciones se desarrollaron en el cuerno uterino derecho, el $47.5 \%$ en el izquierdo y el $4.2 \%$ en ambos. El $42.9 \%$ de las crías fueron hembras y el $57.1 \%$ fueron machos.

Discusión. El hecho de delimitar la temporada de empadre de febrero a junio, y a las hembras que no concibieron en esta temporada ofrecerles tratamiento de horas luz adicional al fotoperíodo durante diciembre y enero, incrementó la incidencia de partos al principio del año. (Rev Biomed 2004; 15:27-31)

Palabras clave: yeguas Pura Sangre Inglés, comportamiento reproductivo, partos al inicio del año.

\section{SUMMARY.}

Reproductive behavior of thoroughbred mares in a farm with deliveries at the beginning of the year.

Introduction. The reproductive behavior of Thoroughbred mares bred in a farm located at $19^{\circ}$ $30^{\prime} \mathrm{N}$ and $119^{\circ} 27^{\prime} \mathrm{W}$, where deliveries are

Solicitud de sobretiros: Dr. en CV Francisco J. Escobar-Medina, Unidad Académica de Medicina Veterinaria y Zootecnia, Universidad Autónoma de Zacatecas. Apartado Postal 11, C.P. 98 500, Calera de Víctor Rosales, Zacatecas, México.

Fax: (01 478) $9850202 . \quad$ E-mail: fescobar@cantera.reduaz.mx.

Recibido el 2/Septiembre/2002. Aceptado para publicación el 3/Diciembre/2003.

Este artículo está disponible en http://www.uady.mx/sitios/biomedic/revbiomed/pdf/rb041515.pdf

Vol. 15/No.1/Enero-Marzo, 2004 


\section{S Vázquez-Dueñas, FJ Escobar-Medina, F de la Colina-Flores, S Hayden-Valles.}

programmed to occur at the beginning of the year was studied.

Materials and methods. The mares were kept in grazing pasture and given supplemental feed on a daily basis. The breeding season runs from February 15 to June 30. From December 1 to January 31, the mares that failed to conceive were exposed to artificial light to extend natural photoperiod.

Results. The $35.7 \%, 17.8 \%, 19.4 \%$ and $12.4 \%$ of parturitions occurred in January, February, March, April, and May, respectively. The intervals from parturition and first estrus, first mating, and conception were 14, 25 and 117 days, respectively. $51.0 \%$ of ovulations occurred in the left ovary, $43.9 \%$ in the right ovary, and $5.1 \%$ showed corpora lutea in both ovaries. $48.3 \%$ of pregnancies developed in the right uterine horn, $47.5 \%$ in the left, and $4.2 \%$ in both. $42.9 \%$ of foals were females and $57.1 \%$ were males.

Discussion. As a result of restricting the mating season to the months of February to June and of exposing the females that failed to conceive in that period to an extended photoperiod during December and January, the incidence of parturitions was higher at the beginning of the year. (Rev Biomed 2004; 15:27-31)

Key words: Thoroughbred mares, reproductive behavior, deliveries at the beginning of the year.

\section{INTRODUCCIÓN.}

Las yeguas son poliéstricas estacionales y el fotoperíodo les programa su actividad reproductiva. En los días con mayor cantidad de horas luz, lo que ocurre en el verano de cada año, estas hembras presentan ciclos estrales y, por consiguiente, pueden concebir. En la temporada en que se reduce el fotoperíodo (invierno) ocurre lo contrario, permanecen en un período anovulatorio no cíclico: anestro (1-4).

Con base en su actividad ovárica y debido a que la duración de la gestación es de alrededor de 11 meses (5), la yegua generalmente presenta sus partos en la primavera (6), como las demás especies con reproducción estacional (7). Esta actividad reproductiva se debe a que en la primavera encuentran las condiciones apropiadas para la supervivencia de su descendencia (7). Sin embargo, no en todas las explotaciones de equinos coincide la fisiología reproductiva de estos animales con el interés de los productores. En algunos criaderos prefieren los partos al principio del año, lo que se puede lograr aplicándoles tratamientos de luz artificial, adicional a la del fotoperíodo natural, en la temporada de días con menor luminosidad. Con este tratamiento se adelanta la temporada de concepciones y, como consecuencia, las yeguas pueden parir en los primeros meses del año (8-10).

Aunque el tratamiento de horas luz para adelantar la temporada de concepciones en la yegua es una práctica que se realiza en algunos criaderos, no se ha evaluado el comportamiento reproductivo de estos animales. Sería interesante conocer la incidencia de partos en los diferentes meses del año y la actividad reproductiva posparto, bajo estas condiciones. El objetivo del presente trabajo fue analizar el comportamiento reproductivo de yeguas pertenecientes a un criadero con partos al principio del año.

\section{MATERIAL Y MÉTODOS.}

El estudio se realizó con yeguas Pura Sangre Inglés de un criadero comercial localizado en Atizapán de Zaragoza, Estado de México, a $19^{\circ} 30^{\prime} \mathrm{N}, 110^{\circ}$ $27^{\prime} \mathrm{O}$ y a $2430 \mathrm{~m}$ snm, durante 13 años. En este criadero, para obtener los partos al principio del año se destinó un período para la temporada de apareamiento, del 15 de febrero al 30 de junio. El resto del año no se realizó la detección del celo en los animales ni se les ofreció monta. Durante la temporada de apareamiento, las hembras se observaron diariamente para identificar a las que presentaran estro; este diagnóstico se realizó con la ayuda de un macho. Las yeguas en celo se sirvieron con monta natural.

Para establecer el momento apropiado para la monta se determinó el tamaño folicular. Este examen se realizó por medio de palpación rectal en los primeros años, y por ultrasonografía en los años recientes. Las yeguas que no concibieron en la

\section{Revista Biomédica}


Comportamiento reproductivo de yeguas.

temporada de apareamiento, se trataron con luz artificial, adicional al fotoperíodo natural, para completar 16 horas luz diariamente, del 1 de diciembre al 31 de enero, y se sirvieron junto con las demás en la temporada de apareamiento siguiente a este tratamiento. Las hembras se mantuvieron en pastoreo y la alimentación se complementó con un producto comercial, de manera que cubrieran sus requerimientos nutricionales.

Para determinar la incidencia de partos en los meses del año y estudiar la eficiencia reproductiva de estos animales, se analizaron 206 ciclos reproductivos, como muestra de 1120 que se registraron durante los 13 años estudiados. El tamaño de la muestra se eligió al azar por medio de un algoritmo generador de números pseudoaleatorios, que permite la selección de elementos de una muestra a partir de un conjunto finito y sin reemplazo, y que asegura el mantenimiento de la probabilidad constante de elegir cualquier elemento a lo largo de todo el proceso (11). Después de haber obtenido la muestra se estimaron el promedio, la varianza de la media de una muestra simple aleatoria y los intervalos de confianza a 95\% (12).

\section{RESULTADOS.}

Los partos se presentaron al inicio del año: el $35.7 \%$ de las yeguas parieron en enero, el $17.8 \%$ en febrero, $19.4 \%$ en marzo, $14.7 \%$ en abril y $12.4 \%$ en mayo; en los meses restantes del año no se presentó ningún parto. La información se puede observar en la figura 1.

La mayor parte de las yeguas $(68.6 \%)$ concibieron sin el tratamiento adicional de horas luz; del total de las hembras, el 64.3\% iniciaron la gestación de marzo en adelante y sólo el $4.3 \%$ concibieron en la segunda quincena de febrero; el resto de las hembras (31.4\%) permanecieron en anestro durante la temporada que se destinó para el empadre y no concibieron hasta el año siguiente, después de 2 meses de tratamiento con luz artificial.

En el Cuadro 1 se presentan los intervalos del parto al primer celo, primer servicio y concepción. El $51.0 \%$ de las yeguas ovularon en el ovario izquierdo, el $43.9 \%$ en el derecho y el $5.1 \%$ en los dos. Las gestaciones se desarrollaron en igual proporción, el $48.3 \%$ en el cuerno uterino derecho, el $47.5 \%$ en el izquierdo y el $4.2 \%$ restante correspondió a gestaciones gemelares, un producto en cada cuerno uterino. Se requirió de 2.83 servicios por concepción y se ofrecieron 1.47 servicios por celo. El $42.86 \%$ (intervalo de confianza $=42.14-43.58$ ) de las crías fueron hembras y el $57.14 \%$ (intervalo de confianza $=56.31$ - 57.97) machos. La duración de la gestación fue de 333 días, en promedio.

\section{DISCUSIÓN.}

La duración media de los intervalos del parto al primer celo y al primer servicio de las yeguas del presente estudio fueron de 14.9 y 25.4 días, respectivamente; lo cual significa que reanudaron su actividad ovárica posparto y se les ofreció servicio en el período establecido para el apareamiento del mismo año en que presentaron el parto. El intervalo del parto al primer celo fue ligeramente más largo al que se ha publicado en otros trabajos, en donde se ha encontrado de 7 a 10 días $(3,13,14)$. Es probable que el ligero retraso en la presentación del primer estro después del parto en las yeguas de este trabajo se debió a que algunas parieron al principio del año, en los días con menor cantidad de horas luz, cuando se reduce el crecimiento folicular. En la yegua, el desarrollo folicular varía de acuerdo a la época del año, se incrementa con el aumento del fotoperíodo $(4,15)$.

Pese a que las yeguas recibieron servicio algunos días después del parto, no todas concibieron

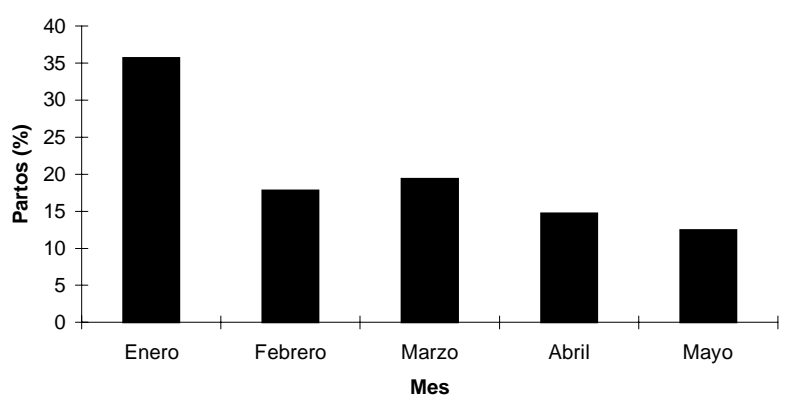

Figura 1.- Distribución de los partos en yeguas Pura Sangre Inglés. 
S Vázquez-Dueñas, FJ Escobar-Medina, F de la Colina-Flores, S Hayden-Valles.

\section{Cuadro 1}

Intervalos del parto al primer celo, primer servicio y concepción en yeguas Pura Sangre Inglés.

\begin{tabular}{|c|c|c|c|c|c|}
\hline $\begin{array}{l}\text { Intervalo del } \\
\text { parto a: }\end{array}$ & $\mathrm{N}$ & $\begin{array}{l}\text { Promedio } \\
\text { (días) }\end{array}$ & $\begin{array}{l}\text { Intervalo de } \\
\text { confianza 95\% }\end{array}$ & $\begin{array}{l}\text { Error estándar } \\
\text { de la media }\end{array}$ & $\begin{array}{l}\text { Intervalo de confianza de las } \\
\text { varianzas de la población }\end{array}$ \\
\hline primer celo & 127 & 14.9 & $12.4-17.4$ & 1.2 & $220.5-385.0$ \\
\hline primer servicio & 126 & 25.4 & $21.8-29.0$ & 1.8 & $456.8-797.4$ \\
\hline $1^{\mathrm{a}}$ concepción & 141 & 117.6 & $90.0-144.0$ & 12.8 & $28709-50116$ \\
\hline
\end{tabular}

$\mathrm{N}=$ Número de ciclos reproductivos

en el período destinado al apareamiento del mismo año. El $31.4 \%$ de las hembras no lo hicieron, permanecieron sin gestación durante el período en que no se detectaron los estros, recibieron tratamiento de luz adicional al fotoperíodo y concibieron hasta el año siguiente. Éstas fueron las que alargaron el intervalo del parto a la concepción. En la yegua, la aplicación adicional de horas luz reprograma la temporada de actividad ovárica $(8,9,10)$, ya que el fotoperíodo influye sobre la fecha de la primera ovulación después del anestro de invierno; el tratamiento con luz artificial como se llevó a cabo en el presente estudio, adelanta significativamente la fecha de la primera ovulación en comparación con las yeguas que se mantienen bajo fotoperíodo natural $(10,16)$.

La mayor parte de los animales (64.3\%) concibieron en el mismo año en que presentaron el parto, sin el tratamiento de luz artificial, porcentaje ligeramente superior al que se ha publicado en esta raza a la misma latitud. González y Valencia (3) encontraron el $55 \%$ de concepciones, de marzo a junio, en yeguas Pura Sangre Inglés mantenidas a $19^{\circ}$ 21 ' de latitud norte, bajo condiciones naturales. La diferencia entre estos valores probablemente se debió a que algunas hembras del presente estudio inicialmente recibieron las horas luz adicionales al fotoperíodo para que concibieran al principio del año, y en ciclos reproductivos subsecuentes continuaron concibiendo en la misma temporada sin el tratamiento. La nutrición, además, también pudo haber influido para que las yeguas mantuvieran este régimen reproductivo. Las hembras del presente estudio se alimentaron con una ración que cubrió sus requerimientos nutricionales. Según los estudios realizados por Fitzgerald y McManus (17), las yeguas con actividad ovárica al principio del año, sin tratamiento de horas luz, presentan mayor concentración de leptina en la circulación sanguínea, mejor peso corporal y más deposición de grasa subcutánea en comparación con las hembras que manifiestan anestro; es decir, se encuentran en mejor estado nutricional. La leptina es la hormona peptídica que se produce en el tejido adiposo (18) cuyo efecto principal lo parece ejercer sobre el sistema neuroendocrino encargado de regular la secreción de gonadotropinas (19).

Las yeguas del presente estudio presentaron 2.83 servicios por concepción, lo cual de alguna manera coincide con la información publicada en la literatura. En estas hembras, la fertilidad del primer celo es baja y se incrementa conforme transcurren los estros después del parto (20-23). La duración de la gestación fue similar a los resultados de otros autores (5), así como el porcentaje del sexo de las crías $(3,4)$.

Los resultados del presente estudio sugieren que delimitar la temporada de empadre de febrero a junio, y a las yeguas que no conciben en el mismo año del parto tratarlas con horas luz adicional al fotoperíodo durante diciembre y enero, incrementa la incidencia de nacimientos al principio del año.

\section{REFERENCIAS.}

1.- Ginther OJ. Occurrence of anestrus, estrus, diestrus and ovulation over a 12-month period in mares. Am J Vet Res 1974; 35: 1173-9.

\section{Revista Biomédica}




\section{Comportamiento reproductivo de yeguas.}

2.- Neely DP. Reproductive endocrinology and fertility in the mare. En: Neely DP, Liu IKM, Hillman RB, editores. Equine Reproduction. Nutley, New Jersey: Hoffman-La Roche; 1983. p. $11-22$

3.- González MAF, Valencia MJ. Estudio del comportamiento reproductivo de la yegua en México. Veterinaria México 1977; 8: 19-22.

4.- Orozco JL, Escobar MFJ, de la Colina FF. Actividad reproductiva de la yegua y la burra durante los días con menor cantidad de horas luz. Veterinaria México 1992; 23: $47-$ 50 .

5.- Hintz HF, Hintz RL, Lein DH, Van Vleck LD. Length of gestation periods in Thoroughbred mares. Equine Med Surg 1979; 3: 289-92.

6.- Escobar MFJ. Comportamiento reproductivo de la yegua y la burra. Veterinaria Zacatecas 1997; 1: 22-6.

7.- Bronson FH, Heideman PD. Seasonal regulation of reproduction in mammals. En: Knobil E, Neill JD, editores. The Physiology of Reproduction. $2^{\text {nd }}$ ed. New York: Raven Press; 1994. p. 541-84.

8.- Kooistra LH, Ginther OJ. Effect of photoperiod on reproductive activity and hair in mares. Am J Vet Res 1975; 36: 1413-9.

9.- Oxender WD, Noden PA, Hafs HD. Estrus, ovulation, and serum progesterone, estradiol and LH concentrations in mares after an increased photoperiod during winter. Am J Vet Res 1977; 38: 203-7.

10.- Scraba ST, Ginther OJ. Effect of lighting programs on onset of ovulatory season in mares. Theriogenology 1985; 24: 667-79.

11.- Knuth DE. Seminumerical algorithms. The art of computer programming. Reading (Mass): Addison Wesley, 1981.

12.- Cochran WG. Técnicas de muestreo. Bogotá, Colombia: C.E.C.S.A.; 1978.

13.- Matthews RG, Ropiha RT, Butterfield RM. The phenomenon of foal heat in mares. Aust vet J 1967; 43: 579-82.

14.- Saltiel A, Gutiérrez A, de Buen-Llado N, Sosa C. Cervico-endometrial cytology and physiology aspects of the post-partum mare. J Reprod Fertil 1987; 35 (suppl): 305-9.

15.- Saltiel A, Calderon A, Garcia N, Hurley DP. Ovarian activity in the mare between latitude $15^{\circ}$ and $22^{\circ} \mathrm{N}$. J Reprod Fertil 1982; 32 (suppl): 261-67.

16.- Palmer E, Driancourt MA, Ortavan R. Photoperiodic stimulation of the mare during winter anoestrus. J Reprod Fertil 1982; 32 (suppl): 275-82.

17.- Fitzgerald BP, McManus C. Photoperiodic versus metabolic signals as determinants of seasonal anestrus in the mare. Biol Reprod 2000; 63: 335-40.

18.- Kersten S. Mechanisms of nutritional and hormonal regulation of lipogenesis. EMBO Rep 2001; 2: 282-6.

19.- Barash IA, Cheung CC, Weigle DS, Ren H, Kabigting EB, Kuijper JL, Clifton DK, Steiner RA. Leptin is a metabolic signal to the reproductive system. Endocrinology 1996; 137 : 3144-7.

20.- Merkt H, Gunzel AR. A survey of early pregnancy losses in West German Thoroughbred mares. Equine vet J 1979; 11:256-66.

21.- Bell RJ, Bristol F. Fertility and pregnancy loss after delay of foal oestrus with progesterone and oestradiol-17b. J Reprod Fertil 1987; 35 (suppl): 667-8.

22.- Koskinen E, Katila T. Uterine involution, ovarian activity, and fertility in the post-partum mare. J Reprod Fertil 1987; 35 (suppl): 733-4.

23.- Woods GL, Baker CB, Baldwin JL, Ball BA, Bilinski J, Cooper WL, Ley WB, Mank EC, Erb HN. Early pregnancy loss in brood mares. J Reprod Fertil 1987; 35 (suppl): 455-9. 